

\section{Habitar de nuevo: naturaleza y cultura en las intervenciones de Ishmael Randall}

Víctor Miguel Vich Florez

Pontificia Universidad Católica del Perú vvich@pucp.pe

Lima-Perú

\section{Resumen}

Este ensayo sostiene que la estética de residuo a partir de la cual la obra de Ishmael Randall ha sido constituida, permite una lectura política que se concentra, más allá de la simple denuncia, en la producción de un conjunto de símbolos destinados a promover o adelantar, nuevas formas de habitar el mundo. Luego de comentar varias de sus principales instalaciones, concluye que a la imagen crítica siempre le sucede una imagen utópica, que resulta del intento por forzar una práctica nueva.

Palabras clave: arte peruano, Ishmael Randal, antropoceno.

\section{Abstract}

This essay argues that the aesthetic of residue from which Ishmael Randall's work has been constituted allows a political reading that concentrates, beyond simple denunciation, on producing a set of symbols intended to promote or advance new ways of inhabiting the world. After commenting on several of his central installations, he concludes that the critical image is always followed by a utopian image, resulting from the attempt to force a new practice.

Keywords: Peruvian art, Ishmael Randal, Anthropocene.

En la obra de Ishmael Randall asistimos a una tensión entre el impulso utópico y la denuncia política, entre la constatación de un sistema económico que lo precariza todo y el intento por reescribir la vida a partir de fragmentos encontrados. Desde hace dos décadas, sus instalaciones han destacado por su densidad simbólica, por su cuidado formal y por la manera salvaje en la que la cultura actual — la cultura del antropoceno- es desafiada estéticamente.

Como se sabe, el antropoceno se refiere a una época en la que los cambios geológicos se deben a las acciones humanas. A diferencia de las eras anteriores (como el pleistoceno o el holoceno), donde los cambios respondían a dinámicas internas del planeta, el antropoceno nombra a una etapa que incluye al hombre como factor de transformación en la evolución del mismo. Lo humano, por tanto, es entendido como una fuerza geológica, cuya actividad deja huellas y produce cambios en la atmósfera, en la tierra y en la biología. Hoy, lo humano no actúa sobre la naturaleza, sino que ha quedado inscrito en todas sus dinámicas (Trischler, 2017). 
La obra de Ismael Randall parte de estos cambios, y se constituye desde el resto, desde aquello que ya no sirve porque ha sido arrinconado como la parte desechable de lo que hoy es socialmente valorado. El artista, sin embargo, ha utilizado esos desechos como un punto de partida para visibilizar la crisis del sistema y para, desde ahí, intentar reconstruir nuevas posibilidades vitales. Se trata de asumir el apocalipsis de la contemporaneidad, pero, al mismo tiempo, de buscar nuevas configuraciones culturales.

¿Es posible producir nuevas relaciones entre lo humano y lo no humano? ¿Es viable habitar el planeta de otra manera? ¿Existe alguna manera de relacionarnos con la naturaleza, fuera de la imposición de una racionalidad puramente instrumental y mercantil? Para teóricos como Latour (2017), la naturaleza y la cultura no pueden continuar pensándose como categorías separadas o como mundos enfrentados. Si lo "humano" es aquello que no puede escapar de su condición propiamente natural, entonces entre "naturaleza" y "cultura" no nos hallamos ante dos dominios excluyentes, sino ante una misma realidad dividida en dos partes.

No se trata, sin embargo, de plantear un "regreso" a la naturaleza como si se tratara de una realidad "externa" a la cultura, sino, más bien, de reinventar la forma en la que habitamos el mundo y de redefinir lo que entendemos por humano. La obra de Randall propone vol-

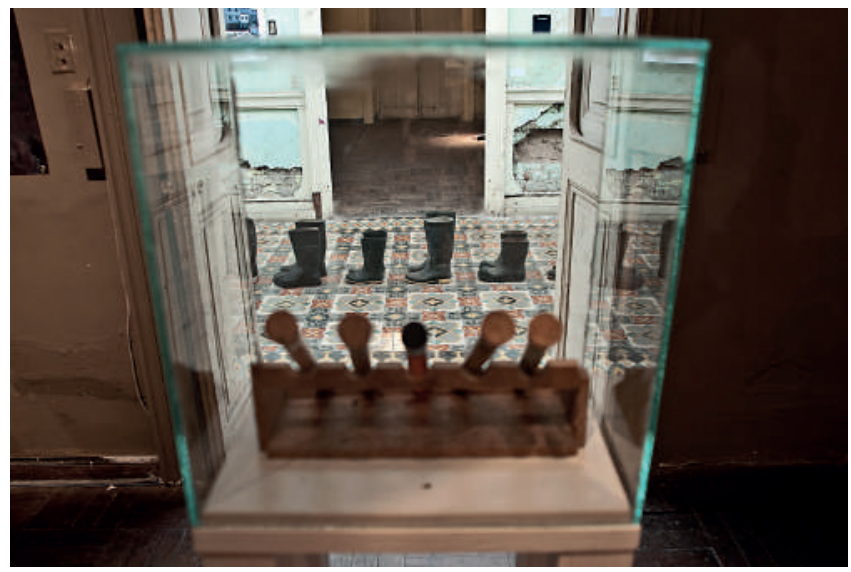

Fig.1. Museo del relave, proyecto Hawapi, 2012. Galleria 80M2 Lima, Perú. Archivo: Ishmael Randall.

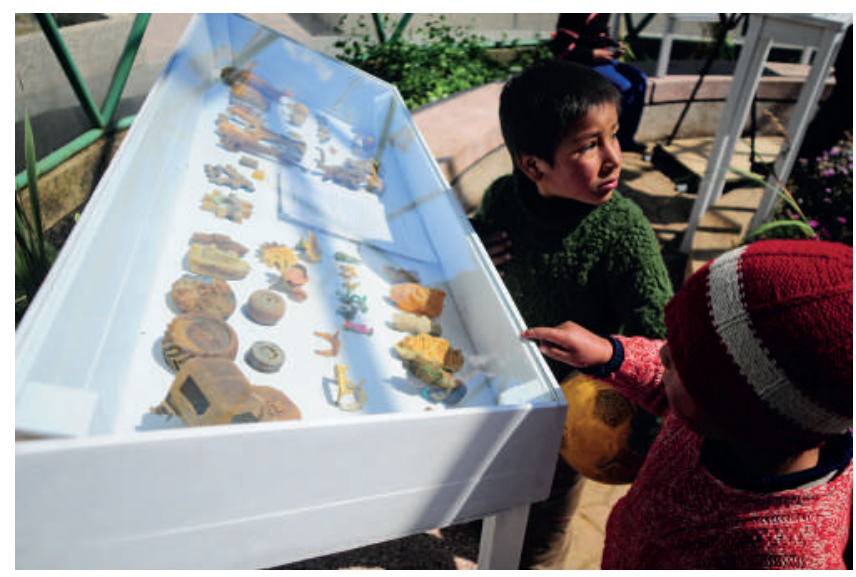

Fig.2. Museo del relave, Cerro de Pasco, 2012. Archivo: Ishmael Randall. ver a habitar el espacio desde nuevas perspectivas bajo una propuesta donde la acción humana es decisiva, pero donde ella ya no está motivada por los mandatos hegemónicos que impone el mundo actual. Randall es un artista que detecta la falla estructural del sistema y es capaz de hacer emerger, dentro de ella, posibilidades nuevas.

Esta necesidad de intervenir el espacio para reinventarlo, vale decir, de habitar de otra forma los lugares, parece ser uno de los motivos centrales a partir del cual se estructura buena parte de su producción plástica. Digamos, teóricamente, que el artista insiste en la necesidad de recuperar la categoría de "lugar" como un condicionante decisivo para repensar tanto las relaciones humanas existentes como las propias definiciones de "cultura" y "naturaleza". Si todo "lugar" establece nuestras formas de ser y de actuar, el 
proyecto simbólico consiste en intervenirlo para repensar la posibilidad de generar nuevas identidades y relaciones sociales.

Lo que deseo comentar en primer lugar no es propiamente una "obra". Se trata de una colección que agrupa distintos residuos de lo que hoy producen las industrias extractivas y cuya existencia da cuenta de la gravísima contaminación ambiental. Titulado el "Museo del relave", esta colección refiere a lo que Gustavo Buntinx (2019) ha llamado una "museotopía”, un tipo de colección que registra y agrupa objetos cuyos intereses van más allá de los propiamente establecidos por el sistema del arte, pues se articulan en torno a una voluntad que está en búsqueda de otro tipo de prácticas, objetivos e imaginarios sociales. En efecto, en esta colección vemos un conjunto de objetos que traen consigo historias diferentes que pugnan por hacerse visibles. Dispuestos al interior de una colección, todos ellos parecen destinados a activar diferentes significados conceptuales, estéticos y políticos.

Recordemos que Beck definió la sociedad contemporánea como aquella donde "lo visible queda a la sombra de las amenazas invisibles" (2010, p. 63), a fin de subrayar cómo las dinámicas de la sociedad producen un conjunto de efectos que no vemos con facilidad y frente a los cuales nunca somos del todo conscientes. "Muchos de los nuevos riesgos se sustraen por completo a la percepción humana inmediata", sostuvo enfáticamente (Beck, 2010, p. 40). Para él, diversos tipos de sustancias nocivas (en el aire, en el agua, en los alimentos), ya pertenecen a nuestro habitar y se constituyen como amenaza permanente.

Digamos entonces que el "Museo del relave" es una intervención para dar cuenta del "otro lado" de la modernidad y del desarrollo capitalista. Todos ellos (por lo general, invisibilizados en las narrativas oficiales) le sirven a la colección para simbolizar el estado del presente (el de la naturaleza, el de la cultura) y mostrar las maneras en las que el actual modelo de desarrollo se fundamenta en la producción de desechos y en lo tóxico. Esta es, en efecto, una colección que se ha propuesto marcar la quemadura del mundo tal como lo habitamos. "Hoy —-sostiene Bauman— solo los residuos tienden a ser sólidos y perdurables” (2006, p. 120).

El objetivo consistió entonces en rastrear las huellas de una modernidad altamente paradójica que, por un lado, produce riqueza y, por otro, contaminación y pobreza. Podríamos decir que aquí cada uno de los objetos (en su silencio, en su simple presentación) cuenta una historia sobre algún tipo de violencia frente a la tierra y frente a la cultura, y que todos emergen como "antimonumentos del progreso" que parecerían estar declarando ante algún tipo de tribunal (Bernabé, 2017, p. 35).

La obra de Randall, sin embargo, no se queda en una estética del archivo o en una opción puramente denunciatoria. Como hemos dicho, su trabajo apuesta, sobre todo, a la construcción de nuevas formas para habitar el mundo. ¿Es posible interactuar con la naturaleza de otra manera? ¿Es posible salir de una lógica puramente extractivista ante la naturaleza?

De hecho, en el marco de permanentes noticias sobre la destrucción del mundo

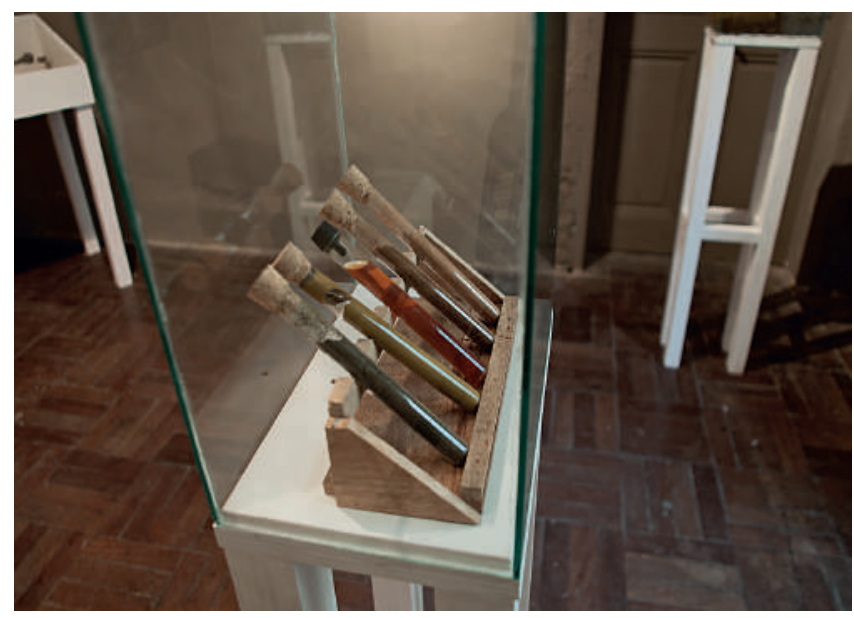

Fig.3. Museo del relave, Proyecto Hawapi, 2012. Galleria 80M2, Lima, Perú. Archivo: Ishmael Randall. 


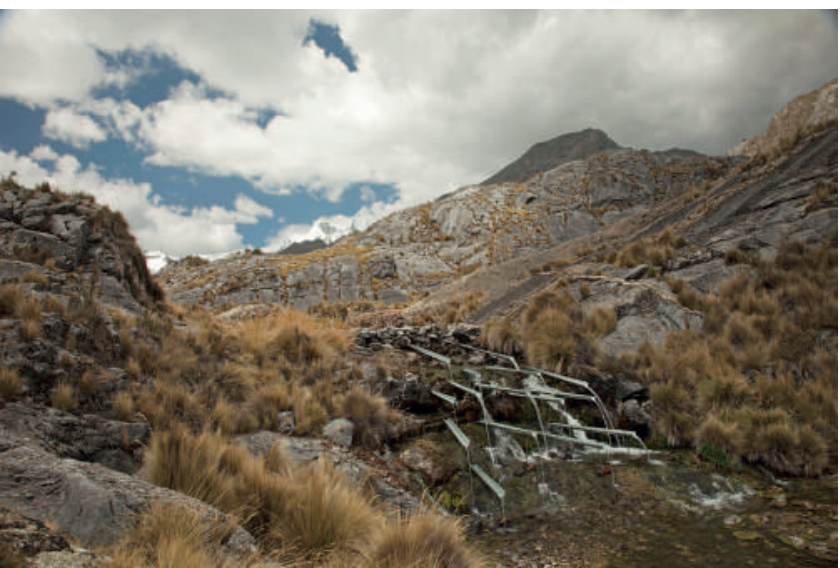

Fig.4. Canaletas, 2014. Proyecto Hawapi 2014, montaña Pariacaca, Junín, Perú Archivo: Ishmael Randall. natural en el Perú, la siguiente intervención destaca por una simplicidad que contrasta con las complejas dinámicas del mundo actual. Fue producida durante una estadía en las faldas del Apu Pariacaca, una de las divinidades mayores en la mitología andina. Como se sabe, el agua de dicha cuenca es una de fuentes que abastecen a una ciudad como Lima, que hoy cuenta con más de once millones de habitantes y que fue construida en medio del de-

sierto. Esta intervención trató de proponer una imagen que condensara la posibilidad de una interrelación distinta entre el hombre y su entorno, una nueva imagen de convivencia.

Es cierto que la vida humana no es posible sin un grado de intervención en la naturaleza (sin un grado de violencia, si se quiere), pero es también verdadero que, más allá de una racionalidad antagónica, se ha vuelto urgente repensar la actual forma de relación con el mundo natural. No se trata de "volver a la naturaleza", sino de proponer nuevas prácticas de interacción con ella en un contexto de verdadera crisis ecológica. De alguna manera, se trata de revelar cómo hoy "la naturaleza esconde su política, cómo la política vuelve la naturaleza explícita” (Latour, 2017, p. 63).

Como podemos observar, el artista nos enfrenta ante una imagen extremadamente simple. Más que extraer, aquí se trata de reconducir. Más que extirpar, se trata de recanalizar. Esta instalación intenta hacer visible la actividad del agua — su permanente movimiento- para contraponerla a aquella imagen que la figura como si fuera un ente "pasivo". De hecho, la modernidad instaló un imaginario donde lo humano es lo activo y la naturaleza su contrario. En estas imágenes, sin embargo, la naturaleza aparece representada en permanente interacción consigo misma y con los hombres.

Por eso, aquí una catarata natural y otra construida por lo humano se superponen en un diálogo muy preciso y poético. Desde ahí, la instalación enfatiza la necesidad de generar nuevo vínculo estético (y productivo) sobre la tierra. Más aún, se intenta promover un momento donde lo natural y lo humano consigan entrelazarse de otra manera para anunciar otro tipo de convivencia. La confluencia del cauce natural con el artificial subraya la necesidad de producir una aprehensión mutua, una relación sensorial entre el agua, la tierra y lo humano.

El símbolo de los canales sirve entonces para deconstruir la oposición entre naturaleza y cultura, y para unificarlas bajo una sola categoría: la de habitar recíprocamente o, mejor dicho, la de "hacer mundo" compartido, tal como Latour lo ha propuesto en uno de sus últimos trabajos (2017, p. 50). ¿Qué significa esto? Digamos que aquí el paisaje emerge como anticipación de algo nuevo y siempre posible.

En un contexto de intensos debates sobre los derechos del agua, estos nuevos cauces ponen en escena la posibilidad de una ingeniería nueva, pero, a la vez, subrayan la fragilidad de todo lo existente. El hombre es siempre un constructor, pero todo lo que hace es siempre reconstruible. Esta imagen es utópica, porque funciona como una especie de "nuevo 
comienzo", vale decir, donde la naturaleza ha dejado de ser una realidad concebida como puramente "exterior" para volver a ser parte integrante de un intercambio metabólico menos violento. ${ }^{1}$

Sin embargo, una imagen contraria de esta problemática, podemos encontrarla en la siguiente intervención realizada en el Morro Solar ubicado en el distrito de Chorrillos, en la ciudad de Lima. Como se sabe, este

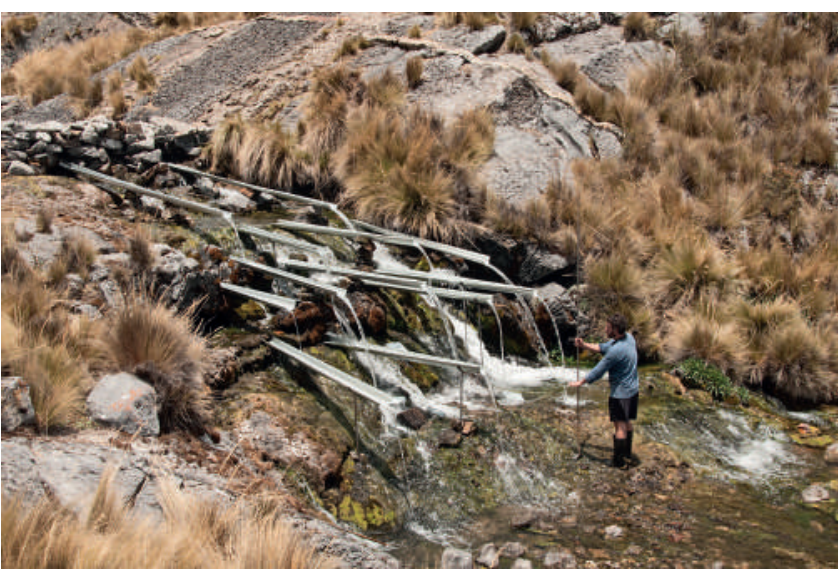

Fig.5. Canaletas, 2014. Proyecto Hawapi 2014, montaña Pariacaca, Junín, Perú. Archivo: Ishmael Randall. lugar no solo ha sido sistemáticamente violentado por la falta de protección ante las invasiones urbanas, sino que hoy lleva además la marca de la corrupción en el Perú: el denominado "Cristo del Pacífico", que fue donado por el consorcio Odebrecht para camuflar sus sobornos bajo el aval del expresidente Alan García. Ishmael Randall propuso entonces construir una simbología que denuncie el conjunto de malas prácticas que se han asentado en dicho lugar y a lo largo de todo el país. Las siguientes fotografías pertenecen a un video disponible en la web en el que puede observarse, con mayor contundencia, el sentido de la propuesta:

Como se sabe, el arrojo de ladrillos rotos, fierros doblados, maderas inservibles y basura ha sido una práctica permanente que ha alterado el paisaje de muchos lugares públicos de la ciudad y el país. Durante mucho tiempo, estas prácticas (sin mayores controles municipales y sin regulación alguna) han destruido espacios naturales y culturales. El llamado Morro Solar no ha sido un lugar de excepción.

No es difícil notar que esta intervención dialoga con el asphalt rundown, que Robert Smithson realizó en 1969, con el objetivo de denunciar una de las catástrofes del mundo moderno. Lo interesante, sin embargo, es que lo que aquí el camión arroja hacia el acantilado no es basura (como se hace cotidianamente en Lima) ni cemento (como en la intervención de Smithson), sino un conjunto de tierra fértil y plantas a las que vemos caer por la ladera. Fueron más de 400 de ellas (entre molles y huarahuays) las que se arrojaron al lugar gracias a las coordinaciones con un vivero de Lurín. La edición del video es muy hábil para alternar distintos planos que consiguen proporcionar una imagen más completa de lo sucedido. Primero vemos el lugar, luego el camión y, finalmente, se nos confronta con esas plantas cayendo sin sentido a lo largo del cerro. El video concluye cuando el camión se retira.

¿Cuál es la analogía entre el acto de tirar basura y arrojar plantas por un acantilado? ¿Qué hay de común entre ambos gestos? En primer lugar, podría sostenerse que se trata de una imagen donde la naturaleza es representada como el "resto" de lo social, vale decir, como aquello que se ha quedado sin lugar en la sociedad moderna. Cercada, agredida y permanentemente desplazada, la naturaleza es entendida por el capitalismo como un estorbo, como algo que hay que subordinar de acuerdo con su lógica siempre expansiva.

1 De hecho, una variante de esta pieza se expuso en el Museo de Arte Contemporáneo de Lima (MAC), donde el artista volvió a instalar los canales, pero con un sistema que reproducía un conjunto de grabaciones sobre el sonido que emite el desplazamiento mismo del agua en dicha cuenca. De manera impactante, la nueva pieza conectaba los dos espacios en el medio de un circuito profundamente sensorial. 

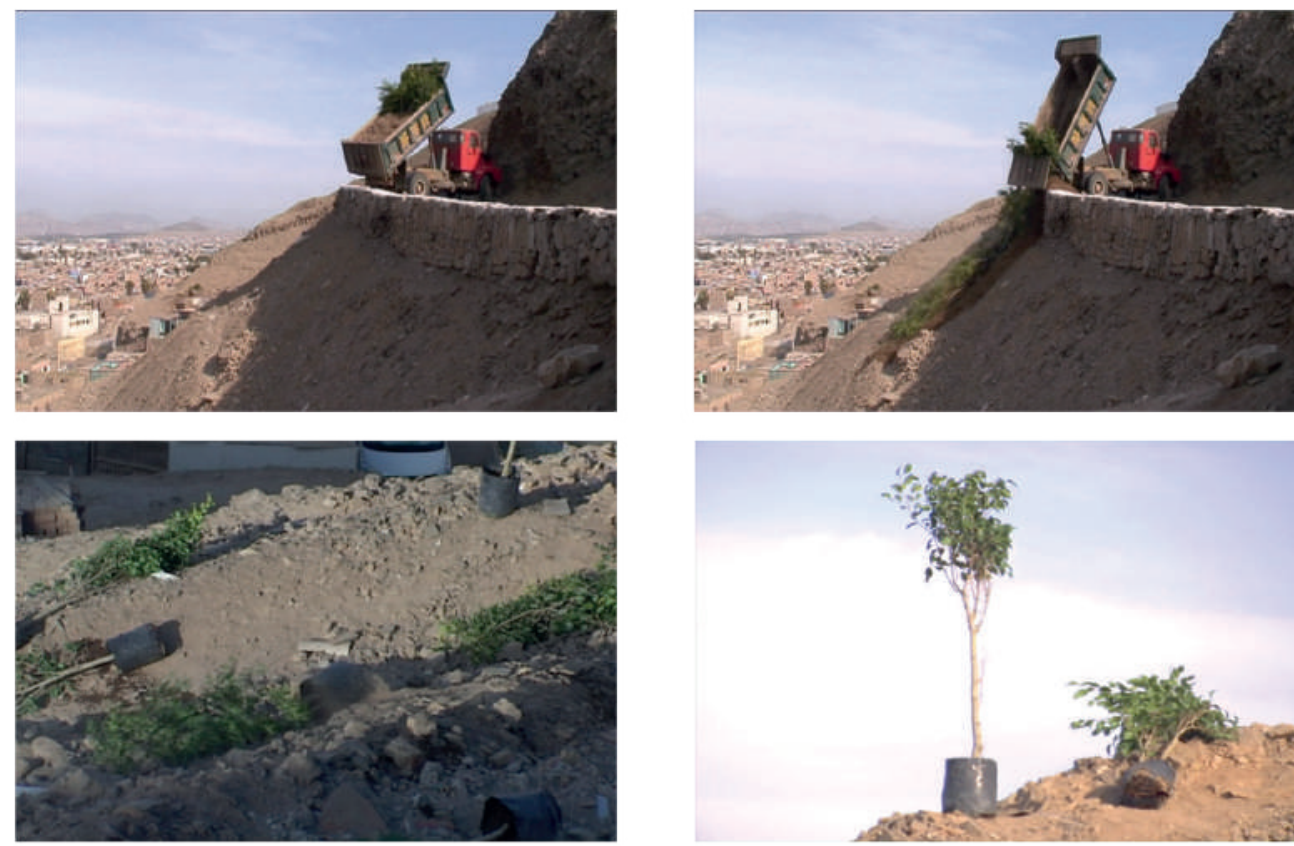

Fig.6. Volquete, 2011. Video, $1 \mathrm{~min} 30 \mathrm{sec}$., Ed.3. Collection Fondazione. Foto: Fondazione Cassa di Risparmio di Modena, Italy. Archivo: Ishmael Randall.

¿Quién es, por lo demás, el que bota este tipo de "basura" que, paradójicamente, consiste aquí en tierra fértil y plantas verdes? Una primera interpretación sostendría que el camión funciona como una metáfora de la sociedad actual, vale decir, de un "modo de producción" que primero saca la naturaleza de su propio lugar y luego busca deshacerse de ella. En efecto, ahogado en la necesidad de producir ganancia a corto plazo, queda claro que hoy el capitalismo se relaciona con la naturaleza como un simple lugar extractivo y luego como un puro estorbo.

Notemos, sin embargo, que esa no es la única interpretación posible. El camión podría representar al arte contemporáneo, en un intento de imitar las dinámicas de poder para luego subvertirlas bajo otros significados. Desde ahí, la intervención estaría proponiendo que hoy es el arte el encargado de arrojar tierra fértil en el medio de una sociedad acostumbrada solo a arrojar basura. Aquí, en efecto, es el arte la práctica que resurge para intentar reparar una dimensión de la sociedad actual. Son entonces las prácticas del arte las que le devuelven a la sociedad su propio gesto invertido. De hecho, el artista me contó que ese mismo día, un dirigente del asentamiento de esa zona (conocida como Alto Perú) recogió muchos de los árboles, comenzó a cuidarlos y con ellos inició la construcción de un pequeño parque que sobrevive hasta la actualidad.

Sin embargo, no es solo la naturaleza lo que ha quedado "sin lugar" en la obra de Ishmael Randall y aparece en crisis: lo mismo parece suceder con el conocimiento o el saber humano. Esta es una sociedad que, en su afán por producir pura rentabilidad, ha comenzado a despreciar el pensamiento y todo conocimiento que ponga en cuestión sus presupuestos. Desentenderse del saber, bajo el puro interés de la ganancia, es la práctica común en el mundo actual. Sabemos, en efecto, que hoy al sistema económico no le interesan las humanidades, el arte, ni el saber propiamente científico, pues muchos de sus hallazgos interrumpen la incontenible dinámica de rentabilidad. 
Es claro que vivimos en una sociedad que reflexiona muy poco sobre sí misma y que, bajo una obsesión inmediatista, desprecia el conocimiento acumulado. Las siguientes imágenes reproducen ese gesto por archivar el saber y por convertirlo en un resto (también sin cabida) bajo la incesante lógica del capital. Por eso, el poder ha optado por censurarlos, cuando no ocultarlos. El artista ha producido notables imágenes al respecto.

Notemos que en estas imágenes la cultura deviene en un juego de fuerzas encontradas. ¿Material "noble" o "innoble"? Hay algo que se clausura, pero también hay algo que está involucrado como soporte. Los pilares, sin embargo, no parecen muy sólidos y se presentan como aquellos que vemos en las innumerables construcciones que existen a lo largo y ancho del Perú. En estas imágenes, Randall consigue producir un gesto dramático sobre la industria de la construcción en el contexto de una sociedad sumida no solo en una grave crisis educativa, sino en una incapacidad para el planeamiento urbano.

Randall, sin embargo, es un artista que siempre está buscando la construcción de signos alternativos, y que no se rinde. Por lo mismo, a la imagen crítica siempre le sucede una imagen utópica (Jameson, 1989). La inmersión en lo degradado lo conduce a forzar una práctica nueva. Y es, bajo ese tipo de opción, que surge la última instalación que quiero comentar en este ensayo.

Construida con grandes cantidades de viejas mayólicas y libros usados, esta es la representación de una nueva ágora ciudadana, vale decir, un lugar para reconstruir y reinventar el lazo social. En efecto, este anfiteatro, esta plaza o este nuevo lugar emergen como una impostergable demanda para la vida colectiva. Se trata de una intervención que entra en diálogo con viejas formas tradicionales, como la chacana andina (un lugar de comunicación que articula cuatro espacios con salidas respectivas) o con los andenes de Maras (lugar en el Cusco donde el artista pasó su

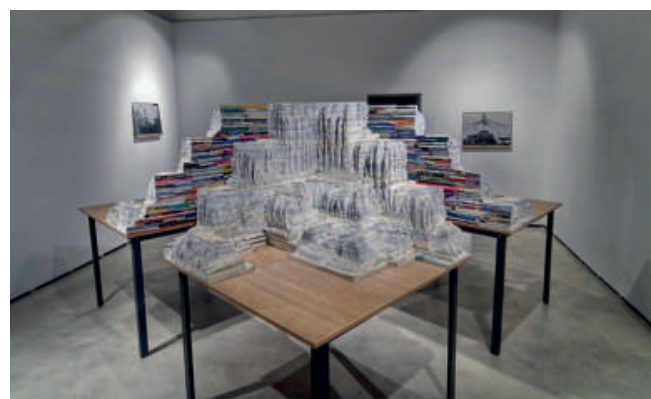

Fig.7. Maquette for landscape, 2010. Cuatro mesas de madera, acero, libros escolares italianos tallados, $300 \times 180 \times 300 \mathrm{~cm}$. Federica Schiavo Gallery, Roma, Italia. Archivo: Ishmael Randall.

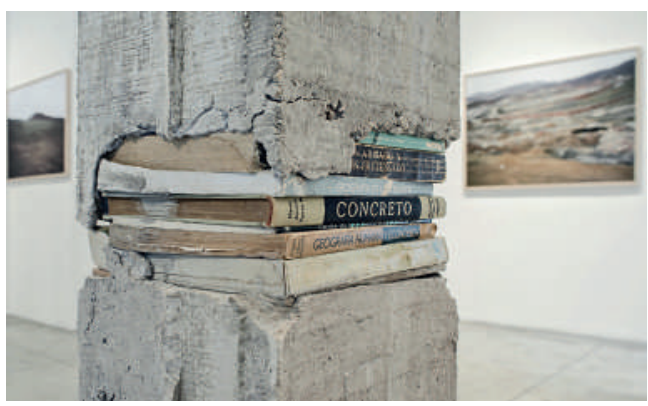

Fig.8. Pilares, 2014. Hormigón armado, libros tallados. Dimensiones variables. Arróniz Galería, México. Archivo: Ishmael Randall.

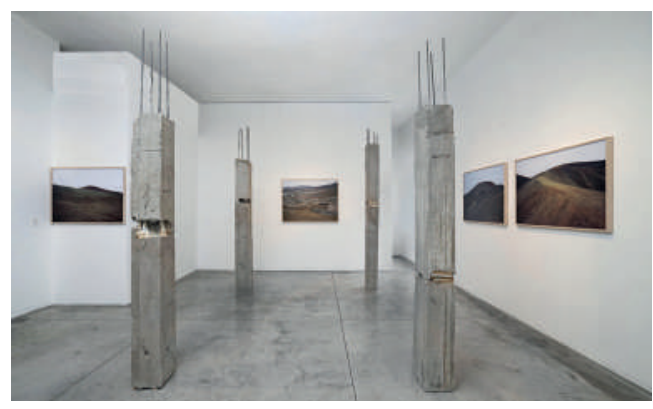

Fig.9. Pilares, 2014. Hormigón armado, libros tallados. Dimensiones variables. Arróniz Galería, México. Archivo: Ishmael Randall.

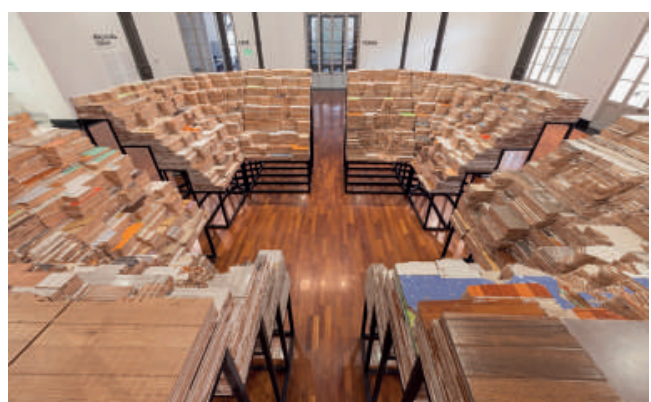

Fig.10. Tribuna, 2017. Mayólicas, libros, acero, 655 x 655 x 240 cm. MALI, Lima, Perú. Archivo: Ishmael Randall. 


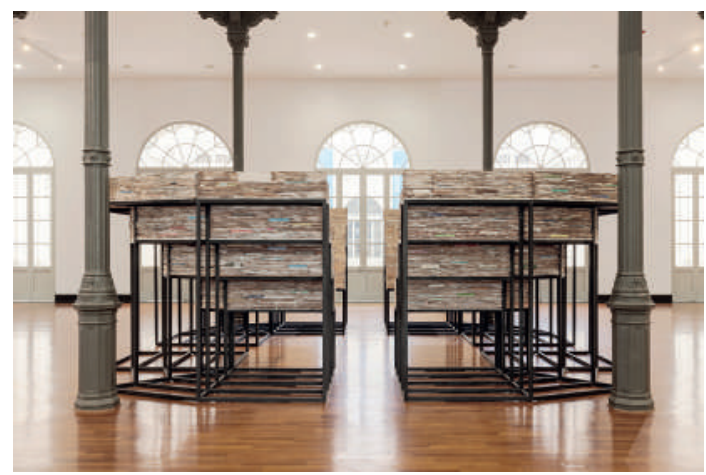

Fig.11. Tribuna, 2017. Mayólicas, libros, acero, 655 x 655 x $240 \mathrm{~cm}$. MALI, Lima, Perú. Archivo: Ishmael Randall.

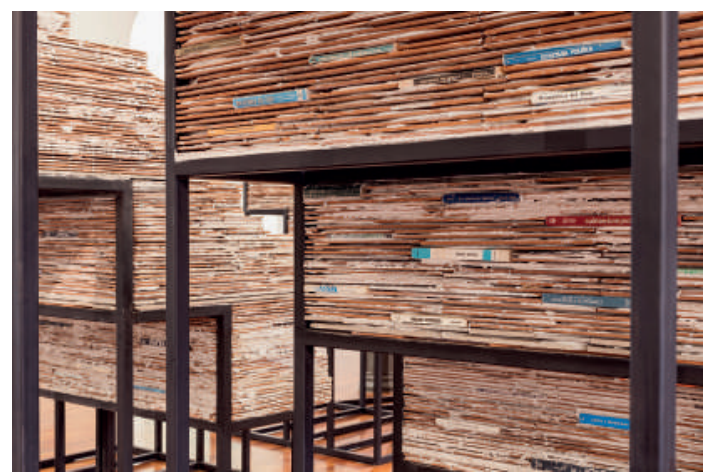

Fig.12. Tribuna, 2017. Mayólicas, libros, acero, 655 x 655 x $240 \mathrm{~cm}$. MALI, Lima, Perú. Archivo: Ishmael Randall. infancia), hoy símbolo de una relación diferente con la naturaleza.

Sostengamos, entonces, que esa pieza se impone como desafío y como reto, como el símbolo de algo que invita a pensar en el rol del saber y de lo público. Nos encontramos ante una nueva imagen sobre el habitar, que entra en contacto con sedimentos y resonancias que vienen del pasado y que empalman con un presente simbolizado por las mayólicas. Nuevamente, y utilizando residuos y desechos, el artista nos enfrenta ante una nueva manera de hilar el pasado con el presente y la tradición con lo nuevo. Esta nueva ágora ciudadana, donde los tiempos dislocados confluyen de manera heterogénea, parece ser una apuesta para convivir de otra manera. ${ }^{2}$

粉米

En suma, la obra de Ishmael Randall simboliza la necesidad de pensar nuevas relaciones estéticas y prácticas con el entorno y con el lugar. Su visión es fundamentalmente práctica, porque construye símbolos alternativos para habitar el mundo. En sus trabajos, lo sensorial se hace presente como un agente decisivo que debe determinar otra forma de construir la relación con la naturaleza. Esta es, en última instancia, una obra que vuelve a colocar la importancia de lo público y del ritual. Digamos que:

Se trata ahora de una coincidencia entre una práctica experimental/proposicional y el lugar que esta práctica cofunda, ya no como objeto inerte, sino como situación móvil y abierta; como espacio-tiempo ensamblado entre las agencialidades del artista propositor, del público interpelado en cuanto operadores participantes y de las materialidades objetuales y corporales que convergen y vibran allí. (Anderman, 2018, p. 254)

En estas imágenes, en efecto, asistimos a un conjunto de representaciones, cuya finalidad consiste no solo en repensar el vínculo con la naturaleza, sino también el lugar de la propia cultura. El artista trabaja a contrapunto con la naturaleza y con la cultura a las que entiende como instancias indisociables. Sus imágenes se desplazan de una dimensión a otra y la tensión no funciona como impase, sino como forzamiento hacia una resolución urgente. Al posicionarse de otra manera ante la naturaleza, se descubre la política inmersa en ella misma y el objetivo es volverla explícita como problema compartido (Latour, 2017).

2 Es una pena que la pieza se esté degradando, sin ningún cuidado, en el patio del Ministerio de Cultura. Llegó ahí para una exposición titulada "Realismos" y, luego de ella, no se la devolvieron al artista, aludiendo "falta de presupuesto" para su movilización. En una entrevista en agosto del 2020, el artista me dijo lo siguiente: "Me interesa producir intervenciones que interrumpan el espacio público; acciones efímeras cuyo destino lo deciden los propios espectadores. Respeto mucho, pero lo mío no es un arte comunitario. Creo, en todo caso, que es muy interesante contemplar cómo la pieza se autodestruye ahí". 
Digamos, en suma, que la obra de Randall devuelve historicidad a las formas de habitar el mundo, pues se ha dedicado a construir símbolos que profanan (y reescriben) las formas habituales de conocimiento. "Una negación contiene, a veces en potencia, los elementos primarios de una acción positiva y creadora”, sostuvo José Carlos Mariátegui hace casi un siglo (1977, p. 171). Se trata, por tanto, de una obra que parte desde una concepción materialista para marcar un nuevo reto. Si bien se surge de una clara voluntad estética, los símbolos propuestos conducen siempre a un conjunto de demandas políticas que encuentran elegantes (y contundentes) maneras formales de hacerse presente.

Frente a una hegemonía que se desentiende de lo común, esta es una obra que vuelve a preguntarse por el valor de lo colectivo. ¿Qué es lo colectivo? La respuesta es clara: la naturaleza, el mundo, el propio arte. Ninguno de ellos puede o debe ser propiedad de nadie. ¿Cómo entonces vivir en el antropoceno? ¿Cómo desarrollar prácticas diferentes a las propuestas por el sistema actual? En varias oportunidades, Ishmael Randall ha sostenido que su proyecto consiste en alterar el paisaje "para que el sitio suceda", vale decir, para que el lugar emerja como acontecimiento y como ruptura hacia un nuevo mundo compartido. Pienso que estas instalaciones son decisivas porque parecen conducirnos hacia esa dimensión "donde la vida se retira para reaparecer luego como resto segregado de la historia" (Bernabé, 2017, p. 33). Todas ellas, en efecto, impactan por su voluntad de reconfigurar lo existente hacia otros mundos posibles. Desde la denuncia o desde la utopía, Randall nos sitúa ante un arte que se ha propuesto activar algún tipo de restauración.

\section{Referencias bibliográficas}

Andremann, J. (2018). Tierras en trance. Arte y naturaleza después del paisaje. Santiago de Chile: Metales Pesados.

Beck, U. (2010). La sociedad del riesgo. Hacia una nueva modernidad. Barcelona: Paidós.

Bernabé, M. (2017). Por otro lado. Ensayos en el límite de la literatura. México D. F.: Foem.

Buntinx, G. (2019). "Vacío museal. Medio siglo de museotopías peruanas (1966-2006). (Un resumen)". En: Alberto Servat, et al. Museo del Grabado ICPNA, pp. 96-109. Lima: Instituto Cultural Peruano Norteamericano.

Jameson, F. (1989). "Prefacio” y "La dialéctica de utopía e ideología”. En: Documentos de cultura, documentos de barbarie. Madrid: Visor.

Latour, Br. (2017). Cara a cara con el planeta. Una nueva mirada sobre el cambio climático alejada de las posiciones apocalípticas. Buenos Aires. Siglo XXI.

Mariátegui, J. C. (2017). Figuras y aspectos de la vida mundial III. Lima: Amauta, 1977.

Trischler, Helmuth. El Antropoceno, ¿un concepto geológico o cultural, o ambos? Desacatos 54. Mayo-agosto 2017, pp. 40-57.

Recibido el 2 de agosto de 2020 Aceptado el 19 de septiembre de 2020 